\title{
Hypoxic microenvironment and hepatocellular carcinoma treatment
}

\author{
Ci-Ai Lin, Lin-Lin Chang, Hong Zhu, Qiao-Jun He, Bo Yang \\ Zhejiang Province Key Laboratory of Anti-Cancer Drug Research, College of Pharmaceutical Sciences, Zhejiang University, Hangzhou \\ 310058, Zhejiang, China.
}

\begin{abstract}
Correspondence to: Dr. Bo Yang, Zhejiang Province Key Laboratory of Anti-Cancer Drug Research, College of Pharmaceutical Sciences, Zhejiang University, 866\# Yuhangtang Rd, Hangzhou 310058, Zhejiang, China. E-mail: yang924@zju.edu.cn; Dr. Qiao-Jun He, Zhejiang Province Key Laboratory of Anti-Cancer Drug Research, College of Pharmaceutical Sciences, Zhejiang University, 866\# Yuhangtang Rd, Hangzhou 310058, Zhejiang, China. E-mail: qiaojunhe@zju.edu.cn
\end{abstract}

How to cite this article: Lin CA, Chang LL, Zhu H, He QJ, Yang B. Hypoxic microenvironment and hepatocellular carcinoma treatment. Hepatoma Res 2018;4:26. http://dx.doi.org/10.20517/2394-5079.2018.27

Received: 22 Mar 2018 First Decision: 17 May 2018 Revised: 9 Jun 2018 Accepted: 9 Jun 2018 Published: 29 Jun 2018

Science Editor: Guang-Wen Cao Copy Editor: Jun-Yao Li Production Editor: Huan-Liang Wu

\begin{abstract}
Hepatocellular carcinoma (HCC) is one of the most rapidly growing and prevalent cancers in the whole world. The characterized hypoxia region inside the HCC tumors has been recently found as the key driver of HCC malignance and treatment failure, leading to a variety of hypoxia-related biological consequences including angiogenesis, metastasis, metabolism deregulation and drug resistance, which ultimately resulted in treatment failure of HCC. This review will summarize the signaling pathways involved in hypoxia-mediated malignance of HCC and discuss current advances of hypoxia-targeted therapies.
\end{abstract}

Keywords: Hepatocellular carcinoma, anti-cancer drugs, hypoxia-targeting strategie

\section{INTRODUCTION}

Hepatocellular carcinoma (HCC) is the sixth most common cancer globally, with a high mortality of 5 -year survival rate less than $10 \%^{[1,2]}$. There are various etiologies implicated in development of HCC, including infection of hepatitis B virus $(\mathrm{HBV})$ or hepatitis $\mathrm{C}$ virus $(\mathrm{HCV})^{[3,4]}$, chronic infection, and alcohol consumption $^{[5]}$. According to the Barcelona Clinic Liver Cancer (BCLC) staging, HCCs can be classified into five stages with each receiving different treatments ${ }^{[1]}$. Effective therapeutic options include liver resection and liver transplantation, ablation and chemoembolization ${ }^{[1]}$. However, for patients often diagnosed with advanced, unresectable or metastatic HCC, chemotherapeutic treatment would be the only option ${ }^{[1]}$. Yet, as reported, significant drug resistance in these patients ultimately resulted in treatment failure ${ }^{[6]}$. 
Hypoxia is a common phenomenon in the intratumor regions of HCC patients ${ }^{[6]}$. Abnormal microvasculature and unrestrained proliferation of HCC cells lead to oxygen deficiency ${ }^{[6,7]}$. Hypoxia is involved in multiple biological process of HCC and promotes tumor aggressiveness, chemoresistance and immunotherapy resistance ${ }^{[8,9]}$. Consequently, the hypoxic microenvironment has been regarded as promising target for HCC treatments. Under hypoxia, hypoxia-induced factors (HIFs) would be stabilized to trigger the transactivation of a series of hypoxia-response genes which promote the malignance of HCC. Thus, the transcription factors HIFs have been regarded as master regulators of hypoxic microenvironment ${ }^{[8]}$. In contrast, several lines of evidence also implicated the HIF-independent hypoxia responses ${ }^{[10-14]}$. Taken together, the mechanisms in HCC progression under hypoxia are complicated and sophisticated. This review will summarize current research advances in hypoxia-mediated molecular mechanism, how hypoxia participates in the progression of HCC and the current intervetion strategies targeting intratumor hypoxia of HCC.

\section{HYPOXIA PLAYS CRITICAL ROLES IN THE PROGRESSION AND MALIGNANCE OF HCC}

Due to the rapid-growing nature of HCC, increased numbers of cells consume increased amount of oxygen, and hypoxia exists in regions of the tumor that are far away from blood vessels ${ }^{[15]}$. Through various signaling pathways, hypoxia further triggers a series of HCC transformation, mediating its angiogenesis, metastasis, metabolism deregulation and drug resistance ${ }^{[6]}$. Hypoxia is a major cause of hypervasculature of HCC by inducing angiogenic factors to stimulate angiogenesis and support tumor growth ${ }^{[15]}$. In addition, a variety of genes would be transactivated under hypoxia by HIFs or the other transcriptional factor and involved in multiple steps of HCC metastasis including epithelial-mesenchymal transition (EMT), invasion of the extracellular matrix, intravasation, extravasation, and secondary growth of the metastases ${ }^{[5]}$. Besides, hypoxia-regulated glycolysis module also contributes to HCC progression ${ }^{[16]}$. Recent study also indicates that hypoxia promotes the differentiation and expansion of immune-suppressive stromal cells, and remodels the metabolic landscape to support immune privilege ${ }^{[9]}$. Therefore, hypoxia can reduce the effectiveness of cancer immunotherapy. Thus, hypoxia microenvironment is highly relevant in HCC development and extensively involved in the process of HCC progression.

\section{MOLECULAR PATHWAYS INVOLVED IN HYPOXIC HCC MALIGNANCE}

The complicated and sophisticated pathways underlying hypoxia have been extensively investigated, and HIFs are identified to play pivotal roles under hypoxia, which has attracted most attention in this field for the last decades ${ }^{[6,8]}$. Yet recently, the findings on the HIFs-independent regulation of tumor angiogenesis and chemoresistance under hypoxic conditions have challenged this notion and raised the possibility that the other important signaling pathways may also participate and promote the progression and malignance of $\mathrm{HCC}^{[10-14]}$. Accumulating evidence shows that Yes associate-Protein (YAP) ${ }^{[17]}$, matrix metalloproteinases (MMPs), high mobility group box 1 (HMGB1) and glucose metabolism enzymes are involved in hypoxiamediated effects in $\mathrm{HCC}^{[18]}$. The above key molecules would be activated as sensors of intratumoral oxygen tension, and trigger the subsequent activation of hypoxia-mediated process, thus may also be regarded as potential targets for HCC therapy.

\section{HIFs-dependent pathways}

HIF system is composed of $\alpha$-subunits and $\beta$-subunits. Under normoxia, HIF1 $\alpha$ is maintained at very low basal activities due to constitutive degradation. Prolyl hydroxylation of HIF1 $\alpha$ by prolyl hydroxylase domaincontaining proteins (PHD1, PHD2 and PHD3) induces its ubiquitination and proteasomal degradation by an E3 ligase ${ }^{[6]}$, von Hippel-Lindau tumor suppressor protein (pVHL). Besides, asparaginyl hydroxylation of HIF1 $\alpha$ by factor inhibiting HIF (FIH) interferes its interaction with transcriptional coactivators, CREB-binding protein (CBP) and $\mathrm{p} 300^{[19,20]}$. Under hypoxia, lacking sufficient oxygen, hydroxylation and proteasomal degradation of HIF1 $\alpha$ are impaired. HIF1 $\alpha$ is stabilized and then translocates into nucleus, 
heterodimerizes with HIF1 $\beta$ and binds core hypoxia-response element [HRE, 5'-(A/G)CGTG-3'] ${ }^{[21]}$. Many HIF target genes play important roles in HCC proliferation, metabolism, angiogenesis, invasion and metastasis ${ }^{[6]}$.

Activation of Wnt/ $\beta$-catenin pathway, PI3K/AKT pathway and SNAIL1 are involved in the epithelial mesenchymal transition (EMT), increasing HCC invasion and metastasis ${ }^{[22,23]}$. As reported, $\beta$-catenin can reinforce the transcriptional activity of HIF1 $\alpha$ and consequently facilitate hypoxia-induced $\mathrm{EMT}^{[24]}$. And regulation of BCL9 expression by HIF1 $\alpha$ may explain the crosstalk between Wnt/ $\beta$-catenin signaling and hypoxia signaling pathways ${ }^{[25]}$. Besides, HIF1 $\alpha$ activation can be regulated by PI3K/Akt pathway, and the activation of PI3K/Akt/HIF1 $\alpha$ pathway mediates hypoxia-induced EMT and drug resistance ${ }^{[26,27]}$. HIF1 $\alpha$ also promotes EMT through increasing SNAIL1 transcription in HCC cells under hypoxia ${ }^{[28]}$. Angiogenic factors like VEGF, bone morphogenetic protein 4 (BMP4) and stem cell factor (SCF) can enhance HCC angiogenesis ${ }^{[29]}$. VEGF has been well characterized as a direct target of HIF systems ${ }^{[30]}$, promoting endothelial cell proliferation and migration especially in areas of hypoxia ${ }^{[31,32]}$. Additionally, hypoxia-induced BMP4 expression is regulated by HIF1 $\alpha^{[33]}$ and SCF expression is HIF2 $\alpha$-dependent ${ }^{[34]}$ to promote HCC angiogenesis and metastasis. Many glycolysis-related genes can be transcriptionally activated by HIF1 $\alpha$, such as phosphoglycerate kinase 1 (PGK1), hexokinase-2 (HK2), glyceraldehyde-3-phosphate dehydrogenase $(\mathrm{GAPDH})$ and phosphofructokinase $(\mathrm{PFK})^{[6,16]}$. It indicates that there is an increased glycolysis in the progression of hypoxia HCC to adapt to oxygen deficiency. HIF1 $\alpha$ induces growth factors, including TGF- $\alpha$ and IGF-2, to promote cell proliferation and survival ${ }^{[35]}$. TGF- $\alpha /$ EGFR can be activated by HIF2 $\alpha$ and contribute to sorafenib resistance in HCC cells ${ }^{[31]}$. Besides, HIF1 $\alpha$ regulates the expression of MMPs to induce extracellular matrix degradation and tumor metastasis ${ }^{[36]}$. NKG2D is critical in directing NK cell responses against tumors. Yamada et al. ${ }^{[37]}$ show that hypoxia promotes downregulation of the NKG2D ligand MICA by tumor cells via a HIF1 $\alpha$-dependent mechanism. Under hypoxia and in the presence of TGF- $\beta, C D 4^{+} \mathrm{T}$ cells upregulate Foxp3 through direct binding of HIF1 to Foxp3 promoter region, inducing Treg formation and immune tolerance ${ }^{[38]}$. Taken together, HIF system regulates hypoxic responses of HCC through diverse signaling pathways, and contributes to HCC progression and malignant process.

\section{HIFs-independent pathways}

HMGB1 signaling pathways

HMGB1 is a chromatin-binding nuclear damage associated molecular pattern ${ }^{[39]}$. Its release under hypoxic condition can induce an inflammatory response to promote invasion and metastasis in HCC cells. Under hypoxic, HMGB1 activates TLR4 and RAGE signaling pathways to induce caspase-1 activation. Caspase-1 subsequently mediates the cleavage and release of a series of pro-inflammatory cytokines (IL-1 $\beta$ and IL18), which in turn promote cancer invasion and metastasis ${ }^{[18,40]}$. Moreover, recent studies suggest that HMGB1 can also translocate from the nucleus to the cytosol under hypoxia, and then bind to mtDNA released from damaged mitochondria ${ }^{[39]}$. Subsequent activation of TLR9 signaling pathway promotes HCC proliferation ${ }^{[18,39]}$, indicating a novel mechanism of the involvement of HMBG1 in HCC progression under hypoxia.

\section{Hippo-YAP pathways}

The Hippo pathway is a classical regulator of organ size and regeneration, and YAP is an important transcriptional co-factor locating at the downstream of Hippo pathway ${ }^{[1,42]}$. The activation of YAP promotes survival, chemoresistance, metastasis, and the other malignant properties of $\mathrm{HCC}^{[43]}$. It has been reported in recent studies that hypoxia induces nuclear translocation and activation of YAP in a HIF-independent way, and the subsequent activation of target genes promotes cell survival, resistance to $\mathrm{SN} 38$ and sorafenib in $\mathrm{HCC}^{[17,43]}$. Meanwhile, statins (the inhibitors of hydroxymethylglutaryl-CoA reductase) can suppress YAP target genes and overcome hypoxia-induced resistance to sorafenib ${ }^{[43]}$. Moreover, YAP could also contribute to liver tumorigenesis by inducing HIF1 $\alpha$-dependent aerobic glycolysis ${ }^{[4]}$. HMGB1 is relevant in this process by binding to GA-binding protein alpha $(\mathrm{GABP} \alpha)$ to promote the expression of $\mathrm{YAP}^{[44]}$. 


\section{THERAPEUTIC STRATEGIES TARGETING-HYPOXIA FOR HCC TREATMENT}

Sorafenib is the only effective first-line drug for advanced $\mathrm{HCC}^{[4]}$. However, hypoxia-induced chemoresistance to sorafenib leads to treatment failure ${ }^{[43]}$. Hypoxia also confers resistance to various anticancer drugs in HCC cells, including etoposide, sorafenib, SN38, cisplatin and doxorubicin ${ }^{[6]}$. As hypoxia induces tumor malignant transformation and plays an important role in resistance to radiotherapy and chemotherapy ${ }^{[14]}$, target-hypoxia therapy is reasonable in HCC treatment. There are several approaches to target hypoxic microenvironment. One approach is to design hypoxia-activated bioreductive pro-drugs which would be activated by enzymatic reduction in hypoxic tissue; the other one is to target key molecules specifically activated in hypoxic cells, such as the most studied HIFs inhibitors. In addition, emerging new strategies such as oxygen supplement ${ }^{[46]}$ and vessel normalization ${ }^{[4]}$ were also developed to target the hypoxic cancers.

\section{Bioreductive prodrugs}

Bioreductive prodrugs generally share a common mechanism of activation. They are activated by enzymatic reduction in hypoxic tissue to form cytotoxins, resulting in hypoxia-selective cell killing ${ }^{[48]}$.

OXY111A is a synthetic allosteric effector of hemoglobin- 4 and promotes normoxia in hypoxic tumors ${ }^{[48]}$. OXY111A has been tested in several cancer animal models, showing beneficial outcomes and low side effect profiles ${ }^{[4]]}$. It is also shown to prevent HIF1 $\alpha$ stabilization as well as VEGF production ${ }^{[6]}$. Tirapazamine (TPZ; SR4233) belongs to the aromatic N-oxide family and has been extensively evaluated. TPZ is reported to potentiate the antitumor efficacy of many anticancer drugs ${ }^{[50-54]}$, becoming a promising compound in combination-therapy. In addition, TPZ can also sensitize HCC cells to topoisomerase I inhibitors via cooperative modulation of HIF1 $\alpha^{[54]}$. As a novel hypoxia-activated prodrug, Q6 ${ }^{[55]}$ arrests tumor growth in vivo through dual hypoxia-targeted regulatory mechanisms. Q6 exhibits potent antiproliferative efficacy and induces apoptosis in HCC under hypoxic. Besides, Q6 can induce attenuation of HIF1 $\alpha$ expression through autophagy-dependent degradation pathway as well. Recent study suggests that Q6 induces G2-M arrest and apoptosis via poisoning topoisomerase $\mathrm{II}^{[56]}$. Thus Q6 shows a more potent anti-proliferative effect than TPZ.

\section{Drugs targeting hypoxia related molecules}

As a curcumin analog, diphenyl difluoroketone (EF24) is an effective and promising anticancer compound. EF24 enhance the antitumor effects of sorafenib and overcomes sorafenib resistance through VHL (Von Hippel-Lindau tumor suppressor)-dependent HIF1 $\alpha$ degradation and NF-אB inactivation ${ }^{[6]}$. Generally, EF24 exerts its effects by inhibition of proliferation and induction of apoptosis. It is reported that EF24 induces G2/M arrest and apoptosis by increasing phosphatase and tensin homologue expression (PTEN) in ovarian cancer cells ${ }^{[57]}$. Recently, EF24 has been shown to suppress invasion and migration of HCC cells in vitro via inhibiting the phosphorylation of $\operatorname{src}^{[58]}$. A series of compounds targeting hypoxia HCC are on clinical trials, such as RO7070179 and EZN-2968, both of which are antisense oligonucleotide inhibitors of HIF1 $\alpha^{[31,59]}$. Other compounds like Bufalin (target inhibition of PI3K-AKT-mTOR activity), ENMD-1198 (a microtubule destabilizing agent) and Metformin (an established antidiabetic drug) are involved in the suppression HIF1 $\alpha$ $\operatorname{expression}^{[6,60]}$.

\section{The other treatments}

Hyperbaric oxygen (HBO) treatment can enhance the amount of dissolved oxygen in the plasma and increase $\mathrm{O}_{2}$ delivery to the tissue oxygen, so it can be used to overcome hypoxia. Both recent and previous research studies have shown that $\mathrm{HBO}$ can be inhibitory and reduce cancer growth in some cancer types ${ }^{[46]}$. Granowitz et al. ${ }^{[61]}$ show that $\mathrm{HBO}$ can inhibit benign and malignant human mammary epithelial cell proliferation. In another study, Cheng et al. ${ }^{[4]}$ engineered VNP20009 to express histidine-prolinerich glycoprotein (HPRG) under the control of a hypoxia-induced NirB promoter. HPRG has potent antiangiogenic and tumor vessel normalization properties. Attenuated Salmonella Typhimurium strain VNP20009 preferentially accumulates and replicates in hypoxic tumor regions. They found that VNP20009- 


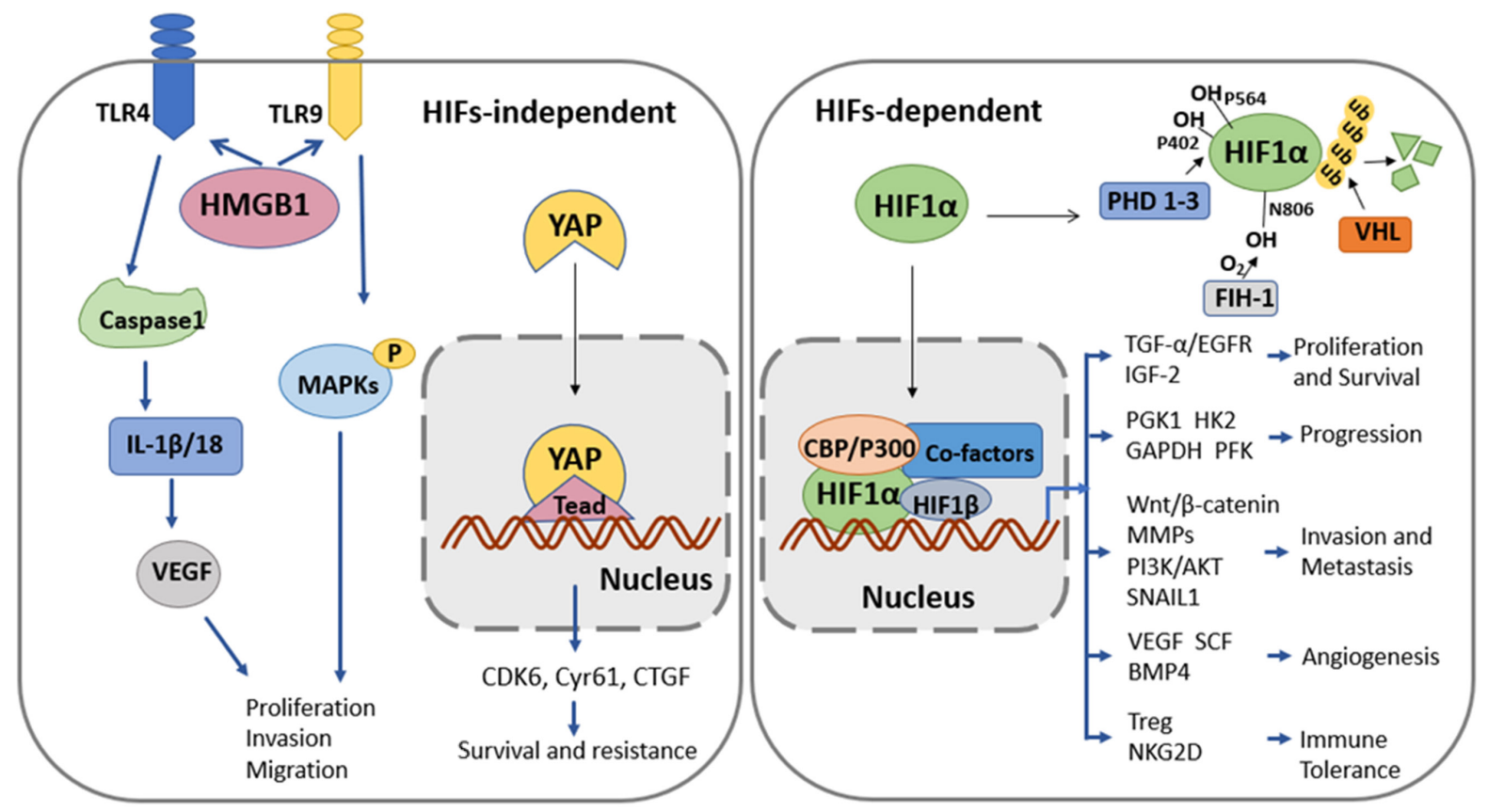

Figure 1. Molecular pathways involved in hypoxia HCC malignance. HCC: hepatocellular carcinoma; YAP: Yes associate-protein; MMPs: matrix metalloproteinases; HMGB1: high mobility group box 1; TLR: Toll-like receptor; IL: interleukin; VEGF: vascular endothelial growth factor; HIF: hypoxia-induced factor; SCF: stem cell factor

mediated targeted expression of HPRG (VNP-pNHPRG) can down-regulate the HIF1 $\alpha$-VEGF/Ang-2 signal pathway by altering the hypoxic tumor microenvironment.

\section{PERSPECTIVES}

Hypoxia is highly relevant in malignant transformation of HCC and activates complicated molecular and cellular pathways through HIF-dependent or independent mechanisms [Figure 1]. Hypoxia promotes angiogenesis, invasion, metastasis, proliferation, glycolysis, drug resistance, inflammation and immune evasion. Consequently, targeting hypoxia has been regarded as promising strategies for HCC treatment. Nonetheless, there is no clear clinical evidence of efficient outcome of anti-cancer treatment due to the HIFinhibition or the treatment of bioreductive agents. In the field of hypoxia-related studies, several concerns still remain, which need to be fully elucidated in the near future, so as to improve the clinical outcome of HCC patients, particularly those displayed intratumor hypoxia:

1. Mechanism of hypoxia response is not fully elucidated, as some recent studies have reported HIFindependent regulation of hypoxia response. It requires further investigation to further unravel the signaling pathways and crosstalk involved in hypoxic cancer;

2. There's a lack of effective treatment for hypoxic cancer. The efficacy of the bioreductive prodrugs should be improved, probably by selecting clinical cancer patients by appropriate biomarkers. In addition, more targets specifically activated under hypoxia should the exploited to seek more promising therapeutic strategies;

3. There's a problem of heterogeneity. It still remains elusive whether different quantitative levels of hypoxia in the same tumor tissue will represent similar response to hypoxia-targeted therapy. In order to guarantee the effectiveness and preciseness of treatment, we can take into consideration of researches in the relationship between the quantitative hypoxia levels and drug response.

In summary, with more profound investigations on hypoxic microenvironment, highly efficient and highly selective interventions will be developed, which will ultimately benefit those HCC patients with severe intratumoural hypoxia.. 


\section{DECLARATIONS}

\section{Authors' contributions}

Manuscript writing: Lin CA, Chang LL, Zhu H

Manuscript revising: He QJ, Yang B

\section{Availability of data and materials}

Not applicable.

\section{Financial support and sponsorship}

This work was supported by the National Natural Science Foundation for Distinguished Young Scholar of China (No. 81625024).

\section{Conflicts of interest}

All authors declared that there are no conflicts of interest.

\section{Ethical approval and consent to participate}

Not applicable.

\section{Consent for publication}

Not applicable.

\section{Copyright}

(c) The Author(s) 2018.

\section{REFERENCES}

1. Marquardt JU, Thorgeirsson SS. SnapShot: hepatocellular carcinoma. Cancer Cell 2014;25:550-1

2. Wong CC, Kai AK, Ng IO. The impact of hypoxia in hepatocellular carcinoma metastasis. Front Med 2014;8:33-41.

3. Beasley RP. Hepatitis B virus. The major etiology of hepatocellular carcinoma. Cancer 1988;61:1942-56.

4. Rehermann B, Nascimbeni M. Immunology of hepatitis B virus and hepatitis C virus infection. Nat Rev Immunol 2005;5:215-29.

5. Severi T, van Malenstein H, Verslype C, van Pelt JF: Tumor initiation and progression in hepatocellular carcinoma: risk factors, classification, and therapeutic targets. Acta Pharmacol Sin 2010;31:1409-20.

6. Chen C, Lou T. Hypoxia inducible factors in hepatocellular carcinoma. Oncotarget 2017;8:46691-703.

7. Jain RK. Normalization of tumor vasculature: an emerging concept in antiangiogenic therapy. Science 2005;307:58-62.

8. Kasper LH, Boussouar F, Boyd K, Xu W, Biesen M, Rehg J, Baudino TA, Cleveland JL, Brindle PK. Two transactivation mechanisms cooperate for the bulk of HIF-1-responsive gene expression. EMBO J 2005;24:3846-58.

9. Chouaib S, Noman MZ, Kosmatopoulos K, Curran MA. Hypoxic stress: obstacles and opportunities for innovative immunotherapy of cancer. Oncogene 2017;36:439-45.

10. Mizukami Y, Li J, Zhang X, Zimmer MA, Iliopoulos O, Chung DC. Hypoxia-inducible factor-1-independent regulation of vascular endothelial growth factor by hypoxia in colon cancer. Cancer Res 2004;64:1765-72.

11. Choi SB, Park JB, Song TJ, Choi SY. Molecular mechanism of HIF-1-independent VEGF expression in a hepatocellular carcinoma cell line. Int J Mol Med 2011;28:449-54.

12. Ndubuizu OI, Tsipis CP, Li A, LaManna JC. Hypoxia-inducible factor-1 (HIF-1)-independent microvascular angiogenesis in the aged rat brain. Brain Res 2010;1366:101-9.

13. Adamski J, Price A, Dive C, Makin G. Hypoxia-induced cytotoxic drug resistance in osteosarcoma is independent of HIF-1Alpha. PLoS One 2013;8:e65304.

14. Wilson WR, Hay MP. Targeting hypoxia in cancer therapy. Nat Rev Cancer 2011;11:393-410.

15. Kim KR, Moon HE, Kim KW. Hypoxia-induced angiogenesis in human hepatocellular carcinoma. J Mol Med 2002;80:703-14.

16. Hamaguchi T, Iizuka N, Tsunedomi R, Hamamoto Y, Miyamoto T, Iida M, Tokuhisa Y, Sakamoto K, Takashima M, Tamesa T, Oka M. Glycolysis module activated by hypoxia-inducible factor lalpha is related to the aggressive phenotype of hepatocellular carcinoma. Int $\mathrm{J}$ Oncol 2008;33:725-31.

17. Dai XY, Zhuang LH, Wang DD, Zhou TY, Chang LL, Gai RH, Zhu DF, Yang B, Zhu H, He QJ. Nuclear translocation and activation of YAP by hypoxia contributes to the chemoresistance of SN38 in hepatocellular carcinoma cells. Oncotarget 2016;7:6933-47.

18. Xiong XX, Qiu XY, Hu DX, Chen XQ. Advances in hypoxia-mediated mechanisms in hepatocellular carcinoma. Mol Pharmacol 2017;92:246-55.

19. Mahon PC, Hirota K, Semenza GL. FIH-1: a novel protein that interacts with HIF-1alpha and VHL to mediate repression of HIF-1 transcriptional activity. Genes Dev 2001;15:2675-86.

20. McNeill LA, Hewitson KS, Claridge TD, Seibel JF, Horsfall LE, Schofield CJ. Hypoxia-inducible factor asparaginyl hydroxylase (FIH-1) 
catalyses hydroxylation at the beta-carbon of asparagine-803. Biochem J 2002;367:571-5.

21. Semenza GL. Hydroxylation of HIF-1: oxygen sensing at the molecular level. Physiology 2004;19:176-82.

22. Liu L, Zhu XD, Wang WQ, Shen Y, Qin Y, Ren ZG, Sun HC, Tang ZY. Activation of beta-catenin by hypoxia in hepatocellular carcinoma contributes to enhanced metastatic potential and poor prognosis. Clin Cancer Res 2010;16:2740-50.

23. Yan W, Fu Y, Tian D, Liao J, Liu M, Wang B, Xia L, Zhu Q, Luo M. PI3 kinase/Akt signaling mediates epithelial-mesenchymal transition in hypoxic hepatocellular carcinoma cells. Biochem Biophys Res Commun 2009;382:631-6.

24. Zhang Q, Bai X, Chen W, Ma T, Hu Q, Liang C, Xie S, Chen C, Hu L, Xu S, Liang T. Wnt/beta-catenin signaling enhances hypoxiainduced epithelial-mesenchymal transition in hepatocellular carcinoma via crosstalk with hif-1alpha signaling. Carcinogenesis 2013;34:96273.

25. Xu W, Zhou W, Cheng M, Wang J, Liu Z, He S, Luo X, Huang W, Chen T, Yan W, Xiao J. Hypoxia activates Wnt/beta-catenin signaling by regulating the expression of BCL9 in human hepatocellular carcinoma. Sci Rep 2017;7:40446.

26. Jiao M, Nan KJ. Activation of PI3 kinase/Akt/HIF-1alpha pathway contributes to hypoxia-induced epithelial-mesenchymal transition and chemoresistance in hepatocellular carcinoma. Int J Oncol 2012;40:461-8.

27. Fu J, Chen Y, Cao J, Luo T, Qian YW, Yang W, Ren YB, Su B, Cao GW, Yang Y, Yan YQ, Shen F, Wu MC, Feng GS, Wang HY. p28GANK overexpression accelerates hepatocellular carcinoma invasiveness and metastasis via phosphoinositol 3-kinase/AKT/hypoxia-inducible factor-1alpha pathways. Hepatology 2011;53:181-92.

28. Zhang L, Huang G, Li X, Zhang Y, Jiang Y, Shen J, Liu J, Wang Q, Zhu J, Feng X, Dong J, Qian C. Hypoxia induces epithelialmesenchymal transition via activation of SNAI1 by hypoxia-inducible factor -1alpha in hepatocellular carcinoma. BMC Cancer 2013;13:108.

29. Zhu AX, Duda DG, Sahani DV, Jain RK. HCC and angiogenesis: possible targets and future directions. Nat Rev Clin Oncol 2011;8:292301.

30. Forsythe JA, Jiang BH, Iyer NV, Agani F, Leung SW, Koos RD, Semenza GL. Activation of vascular endothelial growth factor gene transcription by hypoxia-inducible factor 1. Mol Cell Biol 1996;16:4604-13.

31. Ju C, Colgan SP, Eltzschig HK. Hypoxia-inducible factors as molecular targets for liver diseases. J Mol Med (Berl) 2016; 94:613-27.

32. Josko J, Gwozdz B, Jedrzejowska-Szypulka H, Hendryk S. Vascular endothelial growth factor (VEGF) and its effect on angiogenesis. Med Sci Monit 2000;6:1047-52.

33. Maegdefrau U, Amann T, Winklmeier A, Braig S, Schubert T, Weiss TS, Schardt K, Warnecke C, Hellerbrand C, Bosserhoff AK. Bone morphogenetic protein 4 is induced in hepatocellular carcinoma by hypoxia and promotes tumour progression. J Pathol 2009;218:520-9.

34. Wang X, Dong J, Jia L, Zhao T, Lang M, Li Z, Lan C, Li X, Hao J, Wang H, Qin T, Huang C, Yang S, Yu M, Ren H. HIF-2-dependent expression of stem cell factor promotes metastasis in hepatocellular carcinoma. Cancer Lett 2017;393:113-24.

35. Semenza GL. Targeting HIF-1 for cancer therapy. Nat Rev Cancer 2003;3:721-32.

36. Okazaki I, Inagaki Y. Novel strategies for hepatocellular carcinoma based on MMPs science. Anticancer Agents Med Chem 2012;12:75363.

37. Yamada N, Yamanegi K, Ohyama H, Hata M, Nakasho K, Futani H, Okamura H, Terada N. Hypoxia downregulates the expression of cell surface MICA without increasing soluble MICA in osteosarcoma cells in a HIF-1alpha-dependent manner. Int J Oncol 2012;41:2005-12.

38. Clambey ET, McNamee EN, Westrich JA, Glover LE, Campbell EL, Jedlicka P, de Zoeten EF, Cambier JC, Stenmark KR, Colgan SP, Eltzschig HK. Hypoxia-inducible factor-1 alpha-dependent induction of FoxP3 drives regulatory T-cell abundance and function during inflammatory hypoxia of the mucosa. Proc Natl Acad Sci U S A 2012;109:E2784-93.

39. Liu Y, Yan W, Tohme S, Chen M, Fu Y, Tian D, Lotze M, Tang D, Tsung A. Hypoxia induced HMGB1 and mitochondrial DNA interactions mediate tumor growth in hepatocellular carcinoma through Toll-like receptor 9. J Hepatol 2015;63:114-21.

40. Yan W, Chang Y, Liang X, Cardinal JS, Huang H, Thorne SH, Monga SP, Geller DA, Lotze MT, Tsung A. High-mobility group box 1 activates caspase-1 and promotes hepatocellular carcinoma invasiveness and metastases. Hepatology 2012;55:1863-75.

41. Valero V 3rd, Pawlik TM, Anders RA. Emerging role of Hpo signaling and YAP in hepatocellular carcinoma. J Hepatocell Carcinoma 2015;2:69-78.

42. Zhao B, Li L, Lei Q, Guan KL. The Hippo-YAP pathway in organ size control and tumorigenesis: an updated version. Genes Dev 2010;24:862-74.

43. Zhou TY, Zhuang LH, Hu Y, Zhou YL, Lin WK, Wang DD, Wan ZQ, Chang LL, Chen Y, Ying MD, Chen ZB, Ye S, Lou JS, He QJ, Zhu $\mathrm{H}$, Yang B. Inactivation of hypoxia-induced YAP by statins overcomes hypoxic resistance tosorafenib in hepatocellular carcinoma cells. Sci Rep 2016;6:30483.

44. Chen R, Zhu S, Fan XG, Wang H, Lotze MT, Zeh HJ 3rd, Billiar TR, Kang R, Tang D. High mobility group protein B1 controls liver cancer initiation through yes-associated protein -dependent aerobic glycolysis. Hepatology 2018;67:1823-41.

45. Llovet JM, Ricci S, Mazzaferro V, Hilgard P, Gane E, Blanc JF, de Oliveira AC, Santoro A, Raoul JL, Forner A, Schwartz M, Porta C, Zeuzem S, Bolondi L, Greten TF, Galle PR, Seitz JF, Borbath I, Häussinger D, Giannaris T, Shan M, Moscovici M, Voliotis D, Bruix J; SHARP Investigators Study Group. Sorafenib in advanced hepatocellular carcinoma. N Engl J Med 2008;359:378-90.

46. Moen I, Stuhr LE. Hyperbaric oxygen therapy and cancer--a review. Target Oncol 2012;7:233-42.

47. Cheng X, Zhang X, Cheng W, Chen J, Ma C, Yang B, Hua ZC. Tumor-specific delivery of histidine-rich glycoprotein suppresses tumor growth and metastasis by anti-angiogenesis and vessel normalization. Curr Gene Ther 2014;14:75-85.

48. Guise CP, Mowday AM, Ashoorzadeh A, Yuan R, Lin WH, Wu DH, Smaill JB, Patterson AV, Ding K. Bioreductive prodrugs as cancer therapeutics: targeting tumor hypoxia. Chin J Cancer 2014;33:80-6.

49. Limani P, Linecker M, Kron P, Samaras P, Pestalozzi B, Stupp R, Jetter A, Dutkowski P, Mullhaupt B, Schlegel A, Nicolau C, Lehn JM, Petrowsky H, Humar B, Graf R, Clavien PA. Development of OXY111A, a novel hypoxia-modifier as a potential antitumor agent in patients with hepato-pancreato-biliary neoplasms - protocol of a first Ib/IIa clinical trial. BMC Cancer 2016;16:812.

50. Rischin D, Narayan K, Oza AM, Mileshkin L, Bernshaw D, Choi J, Hicks R, McClure B, Fyles A. Phase 1 study of tirapazamine in combination with radiation and weekly cisplatin in patients with locally advanced cervical cancer. Int J Gynecol Cancer 2010;20:827-33.

51. Emmenegger U, Morton GC, Francia G, Shaked Y, Franco M, Weinerman A, Man S, Kerbel RS. Low-dose metronomic daily 
cyclophosphamide and weekly tirapazamine: a well-tolerated combination regimen with enhanced efficacy that exploits tumor hypoxia. Cancer Res 2006;66:1664-74.

52. Reck M, von Pawel J, Nimmermann C, Groth G, Gatzemeier U. Phase II-trial of tirapazamine in combination with cisplatin and gemcitabine in patients with advanced non-small-cell-lung-cancer (NSCLC). Pneumologie 2004;58:845-9.

53. Johnson CA, Kilpatrick D, von Roemeling R, Langer C, Graham MA, Greenslade D, Kennedy G, Keenan E, O’Dwyer PJ. Phase I trial of tirapazamine in combination with cisplatin in a single dose every 3 weeks in patients with solid tumors. J Clin Oncol 1997;15:773-80.

54. Cai TY, Liu XW, Zhu H, Cao J, Zhang J, Ding L, Lou JS, He QJ, Yang B. Tirapazamine sensitizes hepatocellular carcinoma cells to topoisomerase I inhibitors via cooperative modulation of hypoxia-inducible factor-1alpha. Mol Cancer Ther 2014;13:630-42.

55. Liu XW, Cai TY, Zhu H, Cao J, Su Y, Hu YZ, He QJ, Yang B. Q6, a novel hypoxia-targeted drug, regulates hypoxia-inducible factor signaling via an autophagy-dependent mechanism in hepatocellular carcinoma. Autophagy 2014;10:111-22.

56. Chang L, Liu X, Wang D, Ma J, Zhou T, Chen Y, Sheng R, Hu Y, Du Y, He Q, Yang B, Zhu H. Hypoxia-targeted drug Q6 induces G2-M arrest and apoptosis via poisoning topoisomerase II under hypoxia. PLoS One 2015;10:e0144506.

57. Selvendiran K, Tong L, Vishwanath S, Bratasz A, Trigg NJ, Kutala VK, Hideg K, Kuppusamy P. EF24 induces G2/M arrest and apoptosis in cisplatin-resistant human ovarian cancer cells by increasing PTEN expression. J Biol Chem 2007;282:28609-18.

58. Zhao R, Tin L, Zhang Y, Wu Y, Jin Y, Jin X, Zhang F, Li X. EF24 suppresses invasion and migration of hepatocellular carcinoma cells in vitro via inhibiting the phosphorylation of Src. Biomed Res Int 2016;2016:8569684.

59. Jeong W, Rapisarda A, Park SR, Kinders RJ, Chen A, Melillo G, Turkbey B, Steinberg SM, Choyke P, Doroshow JH, Kummar S. Pilot trial of EZN-2968, an antisense oligonucleotide inhibitor of hypoxia-inducible factor-1 alpha (HIF-1alpha), in patients with refractory solid tumors. Cancer Chemother Pharmacol 2014;73:343-8.

60. Moser C, Lang SA, Mori A, Hellerbrand C, Schlitt HJ, Geissler EK, Fogler WE, Stoeltzing O. ENMD-1198, a novel tubulin-binding agent reduces HIF-1alpha and STAT3 activity in human hepatocellular carcinoma (HCC) cells, and inhibits growth and vascularization in vivo. BMC Cancer 2008;8:206.

61. Granowitz EV, Tonomura N, Benson RM, Katz DM, Band V, Makari-Judson GP, Osborne BA. Hyperbaric oxygen inhibits benign and malignant human mammary epithelial cell proliferation. Anticancer Res 2005;25:3833-42. 